\title{
Neanura judithae n. sp. from Polish Carpathians, with an updated and illustrated key to all species of the genus Neanura MacGillivray, 1893 (Collembola: Neanuridae)
}

\author{
Adrian SMOLIS \\ Institute of Environmental Biology, University of Wrocław, \\ Przybyszewskiego 63/77, 51-148 Wrocław (Poland) \\ adek@biol.uni.wroc.pl \\ Louis DEHARVENG \\ Institut de Systématique, Évolution et Biodiversité, ISYEB - \\ UMR 7205 CNRS, MNHN, UPMC, EPHE, \\ Muséum national d'Histoire naturelle, Sorbonne Universités, \\ case postale 50, 57 rue Cuvier, F-75231 Paris cedex 05 (France)
}

Published on 31st March 2017

KEY WORDS

Springtails

identification,

Europe,

Tatra Mts

new species.

MOTS CLÉS

Collembole,

identification,

Europe,

monts Tatra,

espèce nouvelle.
urn:Isid:zoobank.org:pub:376FF7C0-A9E0-43BD-A7BA-06FA09BB47CF

Smolis A. \& Deharveng L. 2017. - Neanura judithae n. sp. from Polish Carpathians, with an updated and illustrated key to all species of the genus Neanura MacGillivray, 1893 (Collembola: Neanuridae). Zoosystema 39 (1): 37-47. https:// doi.org/10.5252/z2017n1a5

\begin{abstract}
One new species belonging to the genus Neanura MacGillivray, 1893 was found during taxonomic investigations of Tatra Mts, the highest mountain range in the Carpathians. Neanura judithae n. sp. is characterized by the conspicuous reduction of chaetotaxy on dorsal side of the body. It is closely related to the sympatric species $N$. parva (Stach, 1951), from which it differs in having a non-ogival labrum (vs ogival in $N$. parva) and complete fusion of tubercles Di on the abdominal segment V(vs incomplete in $N$. parva). Furthermore, the new species is distinguished by absence of chaetae De3 on abdominal terga I-III and $2+2$ chaetae Di on abdomen V. An illustrated description and short remarks on the ecology of $N$. judithae n. sp. are presented. Additionally, data on morphology of all known species of the genus are also provided in the key.
\end{abstract}

\section{RÉSUMÉ}

Neanura judithae $n$. sp. des Carpathes polonaises, avec une clé actualisée et illustrée de toutes les espèces du genre Neanura MacGillivray, 1893 (Collembola: Neanuridae).

Une nouvelle espèce du genre Neanura MacGillivray, 1893 a été découverte dans les monts Tatras, massif le plus élevé des Carpathes. Neanura judithae n. sp. est caractérisée par une réduction marquée de la chétotaxie dorsale du corps. Elle est très proche de l'espèce $N$. parva (Stach, 1951) avec laquelle elle vit en sympatrie. Elle en diffère par son labre non-ogival (ogival chez $N$. parva) et la fusion complète des tubercules Di sur le cinquième segment abdominal (incomplète chez $N$. parva). La nouvelle espèce se distingue également de $N$. parva par l'absence de la soie De3 sur les tergites des segments abdominaux II-III, et la présence de $2+2$ soies Di sur Abd V. La nouvelle espèce est décrite et illustrée, avec des informations sur son écologie. Enfin, nous proposons une clé des espèces du genre Neanura avec des données sur leur morphologie. 


\section{INTRODUCTION}

The genus Neanura MacGillivray, 1893 is the oldest taxonomic unit within subfamily Neanurinae Boerner, 1901. Unfortunately, as a consequence, a number of species often significantly dissimilar to each other were classified into the genus (e.g., Bellinger et al. 2016). In 1979, to clarify that situation and to better define this composite and poorly delimited taxon, Cassagnau proposed a new diagnosis (Cassagnau 1979). The author in addition divided Neanura into four subgenera: Neanura sensu stricto, Cryptonura, Endonura, and Deutonura. Shortly afterwards, Deharveng (1982) isolated the genus, upgrading the three other subgenera to generic rank. He also modified the previous diagnosis of Neanura as follows: three ocelli on either side of the head, reduced and simple mouth parts, head with 12 or 14 dorsal tubercles, separate lateral tubercles So and $(\mathrm{L}+\mathrm{Dl})$ on head, posterior chaetotaxy of the cross-type on head, separate tubercles Di on abdomen IV, three or four tubercles on abdomen $\mathrm{V}$ (separate or fused tubercles $\mathrm{Di})$, and no cryptopygy. Thenceforth the genus included six species only, namely: $N$. muscorum (Templeton, 1835) - its type species; N. parva (Stach, 1951); N. alba Törne, 1956; N. minuta Gisin, 1963; N. pseudoparva Rusek, 1963; and $N$. pallida Deharveng, 1979. A seventh species, $N$. moldavica Buşmachiu \& Deharveng, 2008, was added subsequently to the list of species of the genus. Noteworthy, except the cosmopolitan $N$. muscorum, all remaining species have relatively narrow geographic distributions that are predominantly limited to central Europe. Considering the closest relatives of Neanura, the Siberian genus Kalanura Smolis, 2007, seems to be its best sister group candidate. These morphologically similar genera (Smolis 2007; Mayvan et al. 2015) differ notably in arrangement of lateral tubercles on head (tubercle Dl fused at least partly to L in Neanura vs separate in Kalanura) and the length of chaetae A and B (same length in Neanura vs chaeta A shorter than B in Kalanura).

In the present contribution a new species of the genus is described. Its description is accompanied by detailed illustrations and photographs including photos of its locus typicus The work contains in addition a key for the identification of all Neanura species. This key is based on extensive materials of all known species, including types of $N$. alba, N. minuta, $N$. moldavica, $N$. pallida, and N. parva.

\section{MATERIAL AND METHODS}

Specimens were collected from soil, litter and decaying wood samples. Samples were extracted using a Berlese-Tullgren apparatus. Obtained specimens were cleared in Nesbitt's fluid, subsequently mounted on slides in Swan's medium and studied using a Nikon Eclipse E600 phase contrast microscope. Figures were drawn with camera lucida and prepared for publication using Adobe Photoshop CS3.

Terminology and layout of the tables used in the paper follow Deharveng (1983), Deharveng \& Weiner (1984), Smolis \& Deharveng (2006), and Smolis (2008).

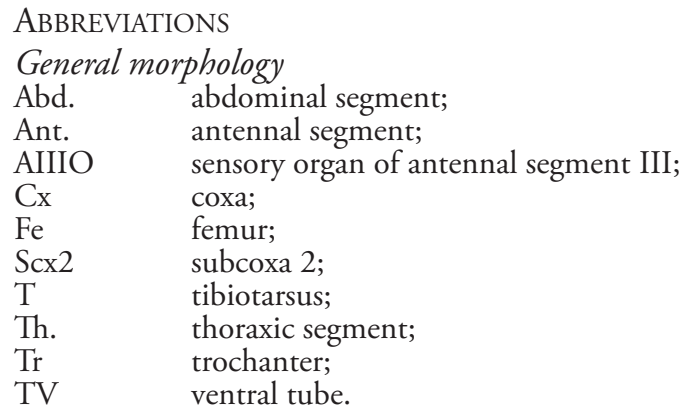

$\begin{array}{ll}\text { Groups of chaetae } \\ \mathrm{Ag} & \text { antegenital; } \\ \mathrm{An} & \text { chaetae of anal lobes; } \\ \text { ap } & \text { apical; } \\ \text { ca } & \text { centroapical; } \\ \mathrm{cm} & \text { centromedial; } \\ \mathrm{cp} & \text { centroposterior; } \\ \mathrm{d} & \text { dorsal; } \\ \mathrm{Fu} & \text { furcal; } \\ \text { vc } & \text { ventrocentral; } \\ \text { Ve or ve } & \text { ventroexternal; } \\ \text { Vea } & \text { ventroexternoanterior; } \\ \text { Vem } & \text { ventroexternomedial; } \\ \text { Vep } & \text { ventroexternoposterior; } \\ \text { Vel } & \text { ventroexternolateral; } \\ \text { Vec } & \text { ventroexternocentral; } \\ \text { Vei } & \text { ventroexternointernal; } \\ \text { Vi or vi } & \text { ventrointernal; } \\ \text { Vl } & \text { ventrolateral. }\end{array}$

$\begin{array}{ll}\text { Tubercles } & \\ \text { Af } & \text { antenno-frontal; } \\ \text { Cl } & \text { clypeal; } \\ \text { De } & \text { dorsoexternal; } \\ \text { Di } & \text { dorsointernal; } \\ \text { Dl } & \text { dorsolateral; } \\ \text { L } & \text { lateral; } \\ \text { Oc } & \text { ocular; } \\ \text { So } & \text { subocular. }\end{array}$

$\begin{array}{ll}\text { Types of chaetae } \\ \text { MI } & \text { long macrochaeta; } \\ \text { Mc } & \text { short macrochaeta; } \\ \text { Mcc } & \text { very short macrochaeta; } \\ \text { me } & \text { mesochaeta; } \\ \text { mi } & \text { microchaeta; } \\ \text { ms } & \text { s-microchaeta or microsensillum; } \\ \text { S or s } & \text { chaeta s; } \\ \text { bs } & \text { border s-chaeta on ant. IV; } \\ \text { miA } & \text { microchaetae on ant. IV; } \\ \text { iv } & \text { ordinary chaetae on ventral ant. IV; } \\ \text { or } & \text { organite of ant. IV; } \\ \text { brs } & \text { border s-chaeta on ant. IV; } \\ \text { i } & \text { ordinary chaeta on ant. IV; } \\ \text { mou } & \text { cylindrical s-chaetae on ant. IV (“soies mousses"); } \\ \text { x } & \text { labial papilla x; } \\ \text { L } & \text { ordinary lateral chaeta on abd. V; } \\ \text { B4; B5 } & \text { ordinary chaetae on tibiotarsi. }\end{array}$

\section{Institutions}

DIBEC Department of Invertebrate Biology, Evolution and Conservation, Institute of Environmental Biology, University of Wrocław, Poland;

MNHN Muséum national d'Histoire naturelle, Paris;

MSPU Moscow State Pedagogical University, Moscow. 


\section{MATERIAL STUDIED}

During preparing a key and figures the following material of Neanura species were studied:

N. muscorum: numerous individuals, England, "Burnham Beeches" near London, litter in beech forest, 20.VI.2003, Adrian Smolis (preserved in DIBEC); numerous individuals, Poland, East Sudetes, Śnieżnik range, Wapniarka Mt., old quarry, birch shrubs, under bark of rotting logs and in decaying wood, 29.IX, 1.IV, 17.IV, 5.XI.1999, Adrian Smolis (DIBEC); numerous individuals, USA, Oregon State, Oregon Dunes near Florence, sea level, mouth of Berry Creek near Lily Lake, sand bank of Berry Creek, under rotting logs, 29.V.2009, Adrian Smolis (DIBEC).

N. parva: lectotype ơ on slide, Poland, Krakowsko-Wieluńska upland, Cracow, Bielany, under bark of beech log, 16.VIII.1920, Jan Stach (collection of the Institute of Systematics and Evolution of Animals, Polish Academy of Sciences, Cracow, Poland); numerous specimens, Poland, Western Carpathians, Tatra Mts, Waksmundzka valley, $1100 \mathrm{~m}$ alt., Norway spruce forest, litter with mosses, 26.IX.1999, Adrian Smolis (DIBEC); numerous individuals, Poland, Tatra Mts, Tomanova valley, $1300 \mathrm{~m}$ alt., dwarf-pine shrubs, soil under stones, 13.VI.2000, 1.VI.2001, leg. Adrian Smolis (DIBEC).

N. alba: holotype $\odot$ on slide, Republic of Austria, Upper Austria, Kobernauserwald, sample 27, 1953, H. Franz (collection of the Muséum d'Histoire naturelle, Geneva, Switzerland);

N. minuta: holotype ơ on slide, Bosnia and Herzegovina, O' Maoče valley, $370 \mathrm{~m}$ alt., soil under shrubs of Sesleria serbica, 20.VIII.1961, Herman Gisin (collection of the Muséum d'Histoire naturelle, Geneva, Switzerland); numerous specimens, Poland, Western Carpathians, Beskid Sądecki Mts, near Muszyna village, nature reserve "Las lipowy Obrożyska", W slope of Mikowa Mt., 500-600 m alt., oak-hornbeam and beech-fir forest, under bark of decomposed log and in rotting wood, 26-28.IV.1999, Adrian Smolis (DIBEC); numerous individuals, Poland, Western Carpathians, Beskid Niski Mts, near Tylawa village, nature reserve "Przełom Jasiołki", N slope of Ostra Mt., 400-600 m alt., sycamore forest, Carpathian beech forest, oak-hornbeam and Carpathian alder forest, under bark of rotting logs, decaying wood, soil, mosses and litter, 5.V.2000, 28.X.2000, 12.V.2001, 16.VI.2001, Adrian Smolis (DIBEC); juvenile, Hungary, Aggtelek National park, 19.I.1988, Gyorgy Traser (DIBEC).

N. pseudoparva: numerous specimens, Poland, Western Carpathians, Beskid Niski Mts, near Tylawa village, nature reserve "Przełom Jasiołki", N slope of Ostra Mt., 400-600 m alt., sycamore forest, Carpathian beech, oak-hornbeam and alder forest, under bark of rotting logs, decaying wood, soil, mosses and litter, 5.V.2000, 28.X.2000, 12.V.2001, 16.VI.2001, Adrian Smolis (DIBEC); numerous specimens, Poland, Eastern Carpathians, Bieszczady Wysokie Mts, near Komańcza village, nature reserve "Przełom Osławy pod Duszatynem”, NE slope of Karnaflów Mt., 500-600 m alt., Carpathian beech-fir forest, under bark of rotting logs, decaying wood and litter, 30.IV-2.V.2001, Adrian Smolis (DIBEC); numerous individuals, Ukraine, Eastern Carpathians, Chornohora Range, South slope of Howerla Mt.,
$1000 \mathrm{~m}$ alt., Carpathian beech forest, under bark of logs and in rotting wood, 11.IX.1999, Adrian Smolis (DIBEC); numerous individuals, Czech Republic, East Sudetes, Jesioniki Mts, nature reserve "Bilá Opava", $1000 \mathrm{~m}$ alt., beech forest, litter, 21.X.2000, Adrian Smolis (DIBEC).

N. pallida: many specimens, France, Alpes-Maritimes, Gilette, near a bridge on Esteron river, litter and rotten wood, 01.VI.1995. (43.8355N, 7.17541E; alt.160 m) (sample code 06-060), Louis Deharveng (DIBEC)

N. moldavica: three paratypes on slides, Moldova, village Radenii Vechi, natural forest reserve "Plaiul Fagului", 10.IV.2006, Galina Buşmachiu (DIBEC).

\section{SYSTEMATICS}

Family NeAnURIDae Yosii, 1956

Subfamily NEANURINAE Boerner, 1901

Tribe Neanurini Boerner, 1901

Genus Neanura MacGillivray, 1893

TyPe SPECIES. - Achorutes muscorum Templeton, 1835 by original designation.

\section{Neanura judithae n. sp.}

(Fig. 1-3; Table 1)

Type Material. - Poland. The Carpathians, Tatra Mts: Waksmundzka valley, 1100-1300 m alt., Norway spruce forest, litter with mosses, decaying wood, 26.IX.1999, Adrian Smolis, holotype o' on slide and seven paratypes on slides (holotype housed in MNHN; paratypes in DIBEC and MSPU).

Other MATERIAL. - Poland. The Carpathians, Tatra Mts: Roztoka valley, $1300 \mathrm{~m}$ alt., Norway spruce forest, litter with mosses, 27.IX.1999, Adrian Smolis, juvenile on slide; Starobociańska valley, $1400 \mathrm{~m}$ alt., dwarf-pine shrubs, litter, 7.VIII. 2012, Adrian Smolis, \% on slide; Gąsienicowa valley, $1600 \mathrm{~m}$ alt., dwarf-pine shrubs, litter, 31.VII-4.VIII.2014, Adrian Smolis, numerous individuals on slides (DIBEC).

DiAgNOSIS. - Habitus typical of the genus Neanura. Dorsal tubercles present and well developed. Body dark bluish grey. Buccal cone short, labrum non-ogival. Head without chaetae C, D, E, Oca and So1. Tubercles Di and De on Th. I present and separate. Thorax and abdomen without free chaetae. Abd. I-III without chaetae De3. Tubercle $(\mathrm{Di}+\mathrm{Di})$ of abd. $\mathrm{V}$ with $2+2$ chaetae, chaetae Di3 absent. Cryptopygy absent. Male ventral organ present.

ETYMOLOGY. - The species is named in honour of Dr Judith Najt who has contributed so much to the knowledge of Collembola.

DistRIBUTION AND ECOLOGY. - Neanura judithae n. sp. has been collected exclusively in Tatra Mts, where it is resident of native Norway spruce forest (upper montane belt, Fig. 3) and dwarf-pine shrubs (subalpine belt). It inhabits litter, mosses and less frequently decaying wood.

\section{DESCRIPTION}

General (Fig. 1A, B)

Body length (without antennae): 0.55 to $1.65 \mathrm{~mm}$ (holotype: $0.98 \mathrm{~mm}$ ). Habitus typical for the genus, parallel and convex. 


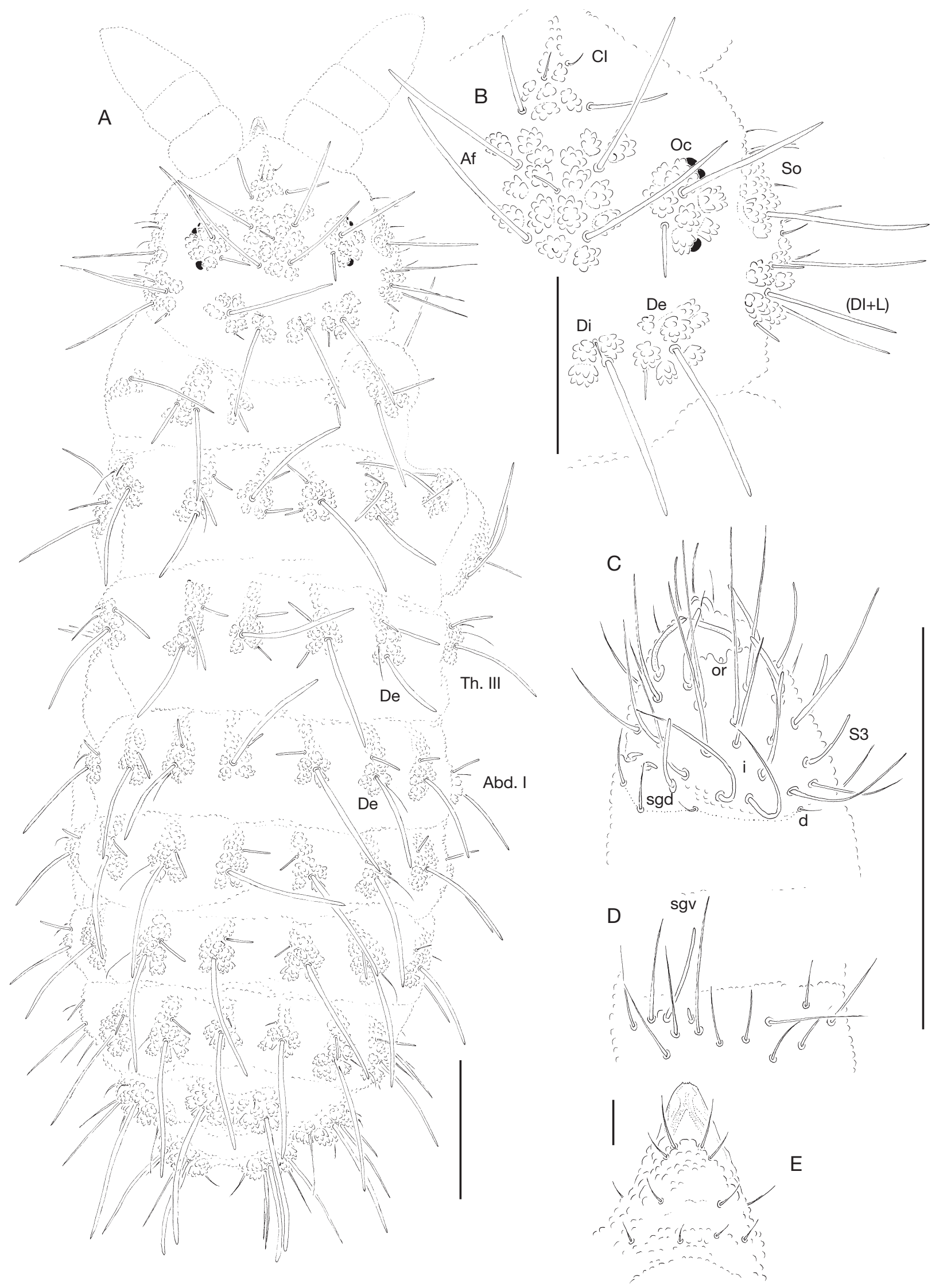

FIG. 1. - Neanura judithae n. sp.: A, dorsal chaetotaxy; B, chaetotaxy of head, dorsolateral view; C, dorsal chaetotaxy of Ant. III-IV; D, ventral chaetotaxy of Ant. III; E, chaetotaxy of labrum. Abbreviations: see Material and methods. Scale bars: A-D, $0.1 \mathrm{~mm}$; E, $0.01 \mathrm{~mm}$. 


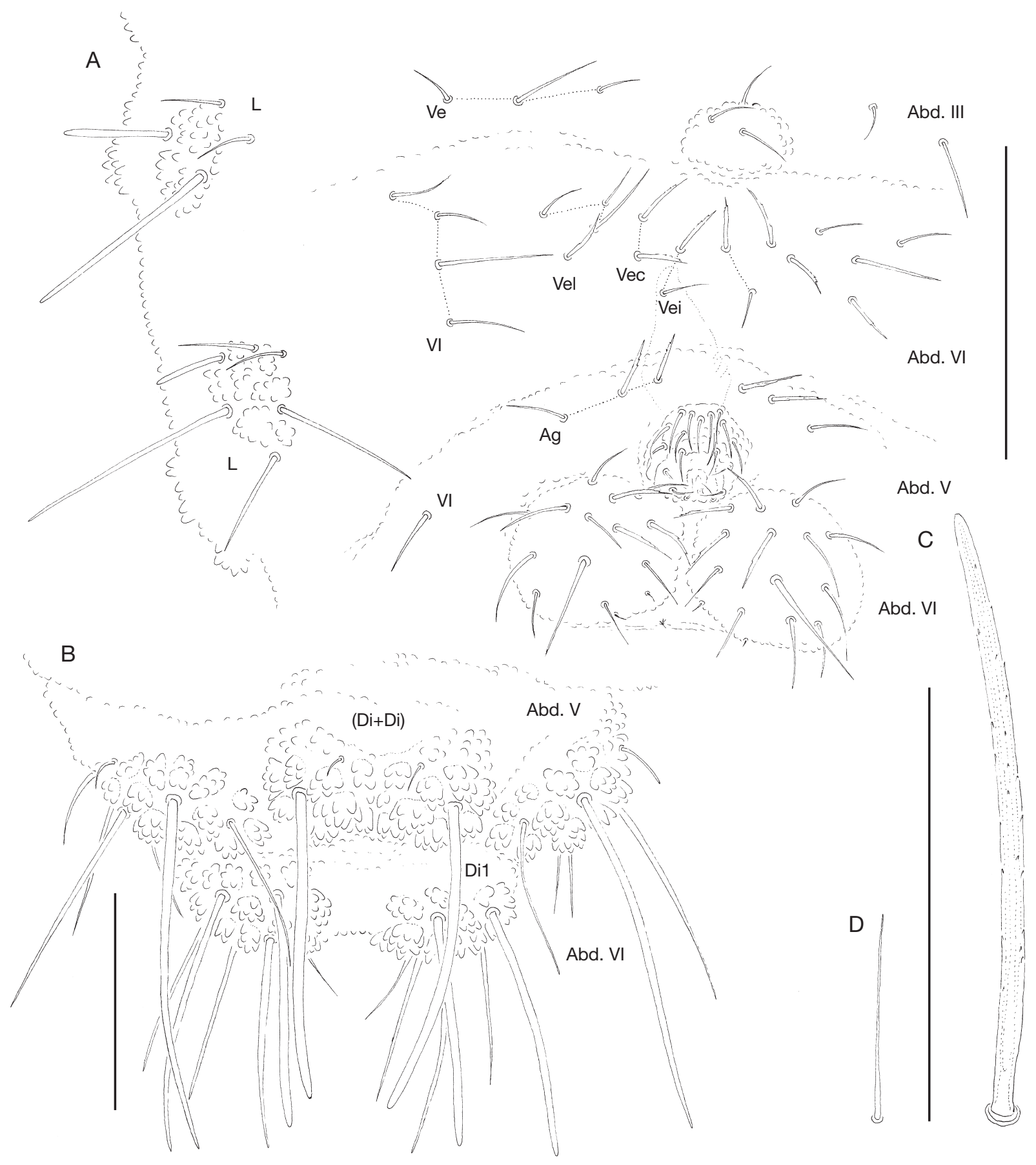

FIG. 2. - Neanura judithae n. sp.: A, ventral chaetotaxy of Abd. III-VI, adult ơ'; B, dorsal chaetotaxy of Abd. V-VI; C, chaeta Di1 of Abd. I; D, sensillum of Abd. V. Abbreviations: see Material and methods. Scale bars: $0.1 \mathrm{~mm}$.

Colour of the body dark bluish grey, rather intense. $3+3$ medium black eyes, in a typical arrangement for the genus (two anterior and one posterior).

Chaetal morphology (Figs 1A, B; 2B-D)

Dorsal ordinary chaetae of five types: long macrochaetae (Ml), short macrochaetae $(\mathrm{Mc})$, very short macrochaetae (Mcc), mesochaetae and microchaetae. Long macrochaetae relatively thick, slightly arc-like or straight, narrowly sheathed, feebly serrated, apically pointed or rounded. Macrochaetae Mc and Mcc morphologically similar to long macrochaetae, but much shorter. Mesochaetae similar to ventral chaetae, thin, smooth and pointed. Microchaetae similar to mesochaetae, but shorter, limited to chaeta Di2 on head and abdominal segments IV-V. S-chaetae of tergites thin, smooth and short, notably shorter than nearby macrochaetae. 
TABLE 1. - Chaetotaxy of N. judithae n. sp.

\begin{tabular}{|c|c|c|c|}
\hline \multicolumn{4}{|c|}{ A, Cephalic chaetotaxy-dorsal side } \\
\hline Tubercle & $\begin{array}{l}\text { Number of } \\
\text { chaetae }\end{array}$ & Types of chaetae & $\begin{array}{c}\text { Names of } \\
\text { chaetae }\end{array}$ \\
\hline \multirow[t]{2}{*}{$\mathrm{Cl}$} & 4 & Mc & $\mathrm{F}$ \\
\hline & & me & $\mathrm{G}$ \\
\hline \multirow[t]{2}{*}{ Af } & 5 & $\mathrm{Ml}$ & $A, B$ \\
\hline & & Mcc & 0 \\
\hline \multirow[t]{2}{*}{ Oc } & 2 & $\mathrm{Ml}$ & Ocm \\
\hline & & $\mathrm{Mc}$ & Ocp \\
\hline \multirow[t]{2}{*}{ Di } & 2 & MI & $\mathrm{Di} 1$ \\
\hline & & Mcc or mi & Di2 \\
\hline \multirow[t]{2}{*}{$\mathrm{De}$} & 2 & MI & De1 \\
\hline & & Mcc & $\mathrm{De} 2$ \\
\hline \multirow[t]{4}{*}{$(\mathrm{DI}+\mathrm{L})$} & 8 & $\mathrm{Ml}$ & Dl1, DI5, L1 \\
\hline & & Mc & L4 \\
\hline & & Mcc & DI6, DI3, DI4 \\
\hline & & $\mathrm{mi}$ & L3 \\
\hline \multirow[t]{2}{*}{ So } & 5 & $\mathrm{Ml}$ & So1 \\
\hline & & me & So3-6 \\
\hline
\end{tabular}

\begin{tabular}{cccc}
\hline \multicolumn{4}{c}{ B, Chaetotaxy of antennae } \\
\hline $\begin{array}{c}\text { Segment, } \\
\text { Group }\end{array}$ & $\begin{array}{c}\text { Number of } \\
\text { chaetae }\end{array}$ & $\begin{array}{c}\text { Segment, } \\
\text { Group }\end{array}$ & $\begin{array}{c}\text { Number of chaetae } \\
\text { adult }\end{array}$ \\
\hline I & 7 & IV & or, $8 \mathrm{~S}, \mathrm{i}, 12 \mathrm{mou}$, \\
II & 12 & & $6 \mathrm{brs}, 2 \mathrm{iv}$ \\
III & 5 sensilla AO III & & $8 \mathrm{bs}, 5 \mathrm{miA}$ \\
ve & 5 & ap & $2 \mathrm{bs}, 3 \mathrm{miA}$ \\
vc & 4 & ca & $3 \mathrm{bs}, 1 \mathrm{miA}$ \\
vi & 4 & $\mathrm{~cm}$ & $8 \mathrm{miA}, 1 \mathrm{brs}$ \\
d & 5 & $\mathrm{cp}$ & \\
\hline
\end{tabular}

\begin{tabular}{|c|c|c|c|c|c|c|c|c|}
\hline \multicolumn{9}{|c|}{ C, Postcephalic chaetotaxy } \\
\hline \multicolumn{5}{|c|}{ Terga } & \multicolumn{4}{|c|}{ Legs } \\
\hline & $\mathrm{Di}$ & $\mathrm{De}$ & DI & L & Scx2 & $\mathrm{Cx}$ & $\operatorname{Tr}$ & $\mathrm{Fe} \mathrm{T}$ \\
\hline Th. I & 1 & 2 & 1 & - & 0 & 3 & 6 & 1319 \\
\hline Th. II & 3 & $3+s$ & $3+\mathrm{s}+\mathrm{ms}$ & 3 & 2 & 7 & 6 & 1219 \\
\hline Th. III & 3 & $3+s$ & $3+s$ & 3 & 2 & 8 & 6 & 1118 \\
\hline
\end{tabular}

\begin{tabular}{lllll}
\hline Abd. I & 2 & $2+\mathrm{s}$ & 2 & 3
\end{tabular}

$\begin{array}{lllll}\text { Abd. II } 2 & 2+\mathrm{s} & 2 & 3 & \text { Ve: } 5 \text { Ve1 present }\end{array}$

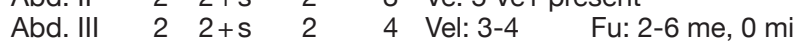

$\begin{array}{lllllll}\text { Abd. IV } & 2 & 2+\mathrm{s} & 3 & 6 & \text { Vl: } 4 & \text { Vel: } 4 \text { Vec: } 2 \text { Vei: } 2\end{array}$

$\begin{array}{llll}\text { Abd. V } & (2+2) \quad 6+\mathrm{s} & \text { Ag: } 3 & \text { Vl: } 1\end{array}$

$\begin{array}{lllll}\text { Abd. VI } & 7 & - & - & -\end{array}$

\section{Antennae (Fig. 1C, D; Table 1B)}

Typical of the genus. S-chaetae of Ant.IV of medium length, subequal and moderately thickened. Apical vesicle distinct, trilobed. Dorsal chaeta d5 absent on ant. III.

\section{Mouthparts (Fig. 1E)}

Buccal cone relatively short with labral sclerifications nonogival. Labrum chaetotaxy: 4/2, 4. Labium with four basal, three distal and four lateral chaetae, papillae $\times$ absent. Maxilla styliform, mandible thin and tridentate.

Dorsal chaetotaxy and tubercles (Fig. 1A, B; 2B; Tables 1A, C) Chaetotaxy of head reduced, chaetae C, D, E, Oca and So 1 absent. Tubercles Di on Th. I differentiated and not fused with tubercles De. Thorax and abdomen without free chaetae. On Th. II-III, chaetae De2 longer than De3. Abd. I-III without chaetae De3. On Abd. I-III, the line of chaetae De1-chaeta $s$ perpendicular to the dorsomedian line. On Abd. V, tubercles Di fused along midline and with $2+2$ chaetae, chaetae Di3 absent. No cryptopygy, Abd. VI well visible from above.

\section{Ventral chaetotaxy (Fig. 2A; Table 1C)}

On head, groups Vea, Vem and Vep with 3-4, 4, 4 chaetae respectively; group $\mathrm{Vi}$ with 6 chaetae. On Abd. IV, furcal rudiment without microchaetae. On Abd. V, chaeta Vl present. Male with thick and forked chaetae ("male ventral organ") on even anal valves (Abd. VI), in groups Ag (Abd. V) and Ve (Abd. IV).

\section{Legs (Table 1C)}

Claw without internal tooth. On tibiotarsi, chaeta $M$ present and chaetae B4 and B5 relatively short (ratio- inner edge of claw: chaeta B4: chaeta B5; 12: 9: 11) and pointed.

\section{REMARKS}

Neanura judithae n. sp. is morphologically most similar to $N$. parva, resembling that species in having a strong reduction of chaetotaxy on head (chaetae Oca, C, D and E absent) and absence of free chaetae on dorsal side of the body. Nevertheless, they are readily distinguished by different shape of labral sclerifications (non-ogival in $N$. judithae n. sp. vs ogival in $N$. parva, Figs 1E; 5F), number of chaetae De on Th. III (4 in $N$. judithae n. sp. vs 5 in $N$. parva), number of chaetae De on Abd. I-III ( 3 in $N$. judithae n. sp. vs 4 in $N$. parva) and number of chaetae Di on Abd. V $(2+2$ in $N$. judithae n. sp. vs $3+3$ in $N$. parva, Figs 2B; 5G). Furthermore, $N$. judithae n. sp. is characterized by complete fusion of tubercles Di on Abd. V (in N. parva tubercles are fused only distally, Fig. 5G).

The new species seems to be a true endemic to the Tatra Mts, whereas $N$. parva has a much larger distribution range, extending across the whole Western and Eastern Carpathians, Sudetes, Southeastern Alps, and some lowland/upland localities in Poland (Smolis pers. comm.).

\section{DISCUSSION}

The genus Neanura is a relatively small taxonomic unit within subfamily Neanurinae, with eight species described up to date. For comparison Deutonura and Endonura, the former subgenera of Neanura, currently comprising 58 and 48valid species respectively (Deharveng et al. 2015; Smolis \& Kuznetsova 2016; Smolis et al. 2016). Interestingly, despite the small number of known Neanura species, their correct identification may pose some difficulties and problems. For this reason we prepared an identification key to all known species, additionally enriched by figures of some diagnostic features. The correct determination can be especially difficult in the case of a pair of species $N$. muscorum and N. pseudoparva. These two sibling species, morphologically hard to separate, are known to live in sympatric populations in central Europe. Their correct identification can be also crucial in the mentioned case as $N$. muscorum has been recently successfully reared under laboratory conditions and, 


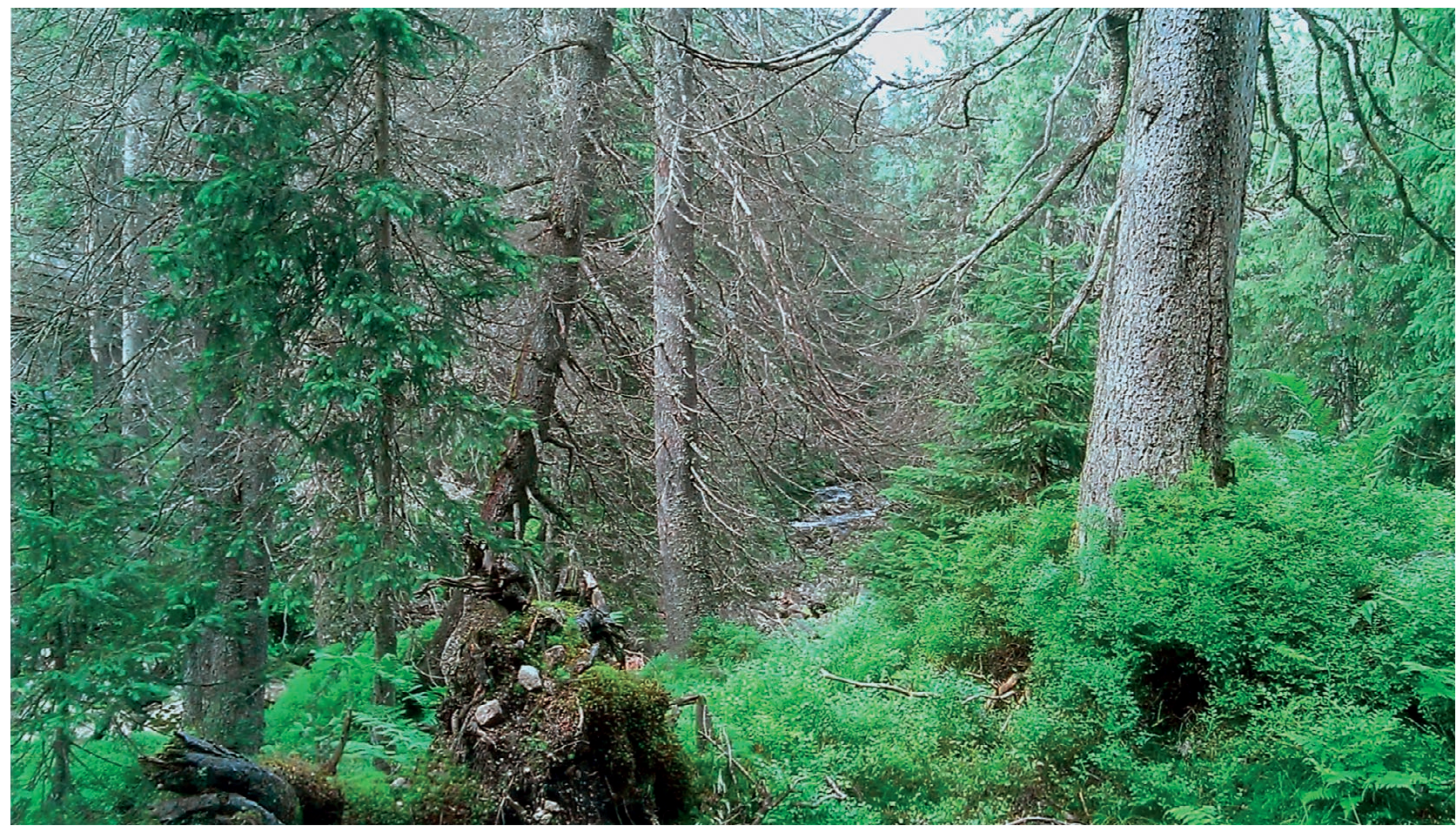

FIG. 3. - Norway spruce forest in Waksmundzka valley, Tatra Mts, the type locality of N. judithae n. sp. Photograph: Adrian Smolis.

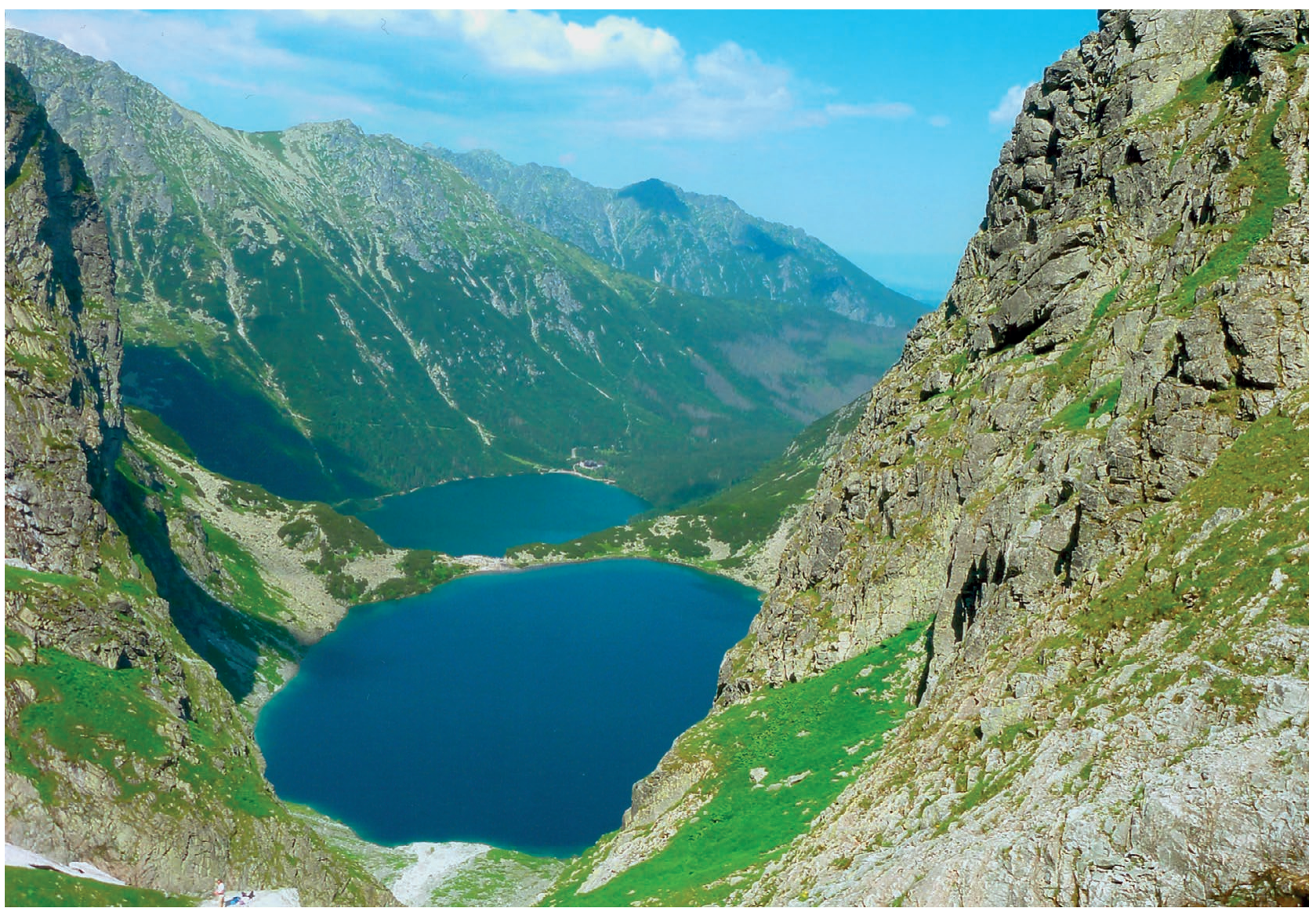

FIG. 4. - The highest parts of Tatra Mts, the northernmost centre of endemism in Europe. Photograph: Adrian Smolis. 
A

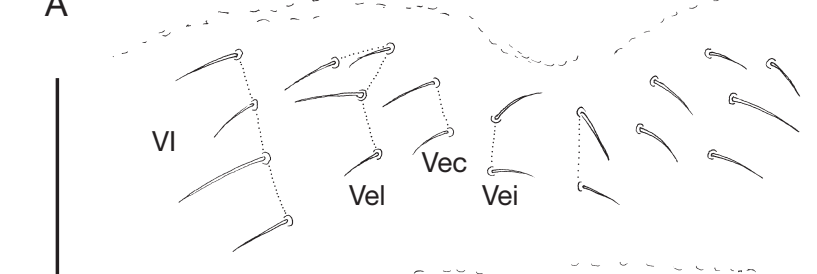

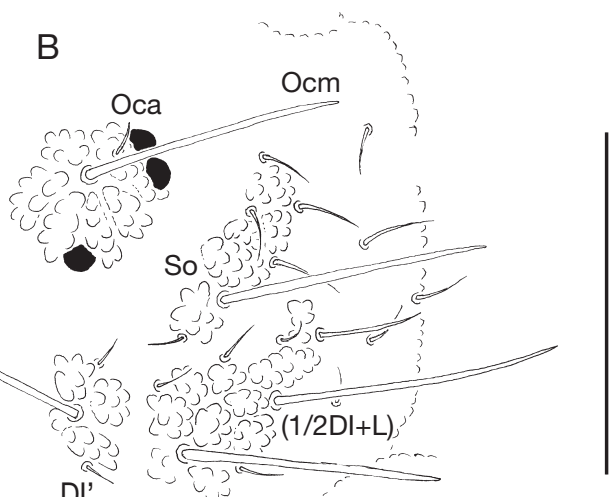

$\mathrm{Di}$

$\mathrm{De}$

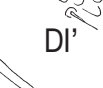

Abd. V $\rho_{\mathrm{L}}$

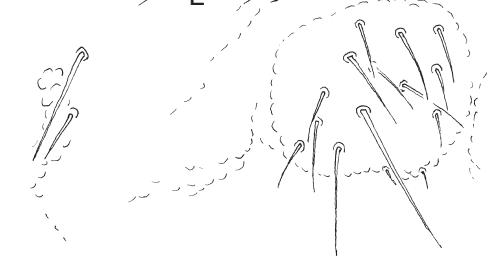

Abd. IV
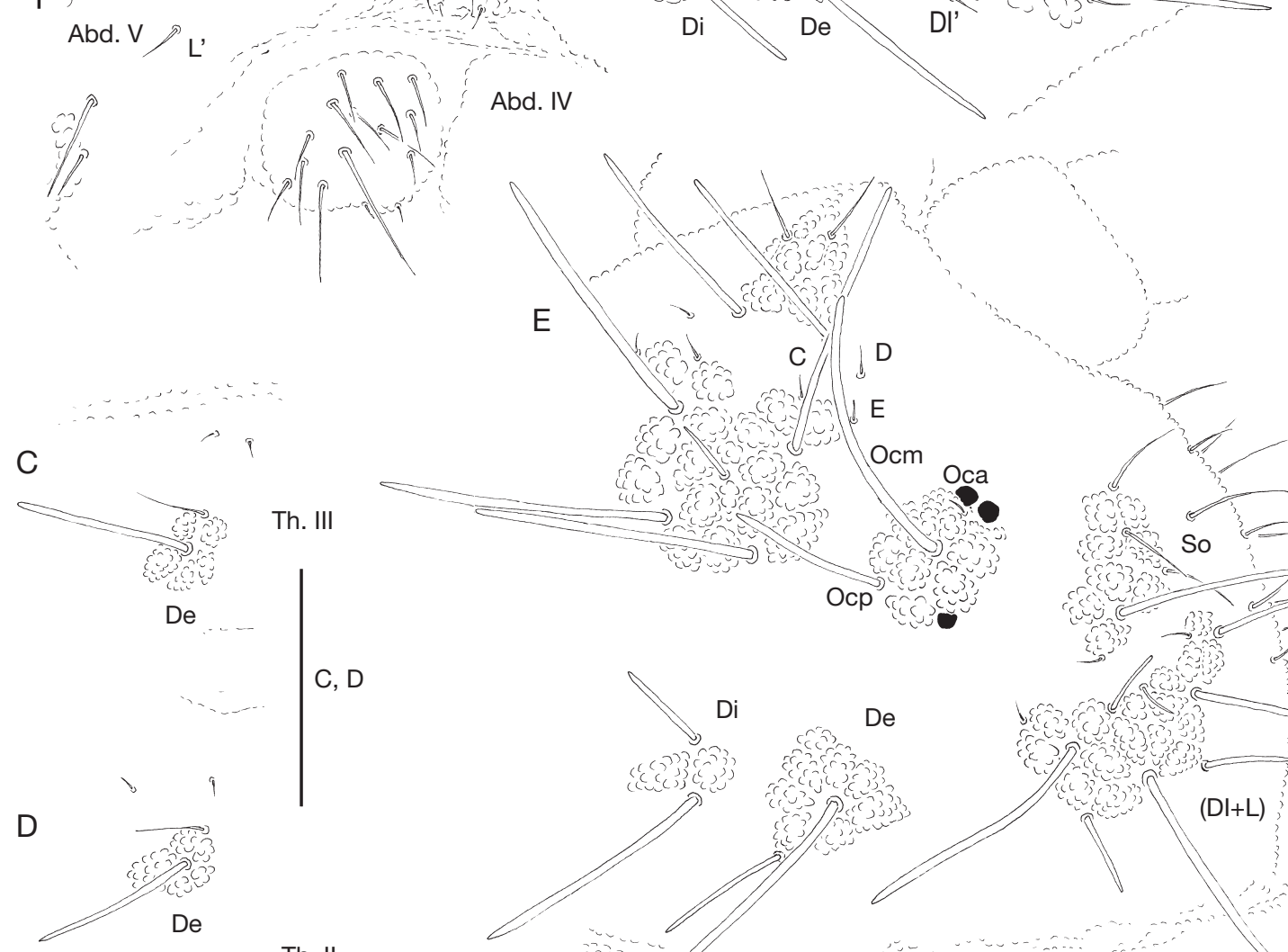

Th. II
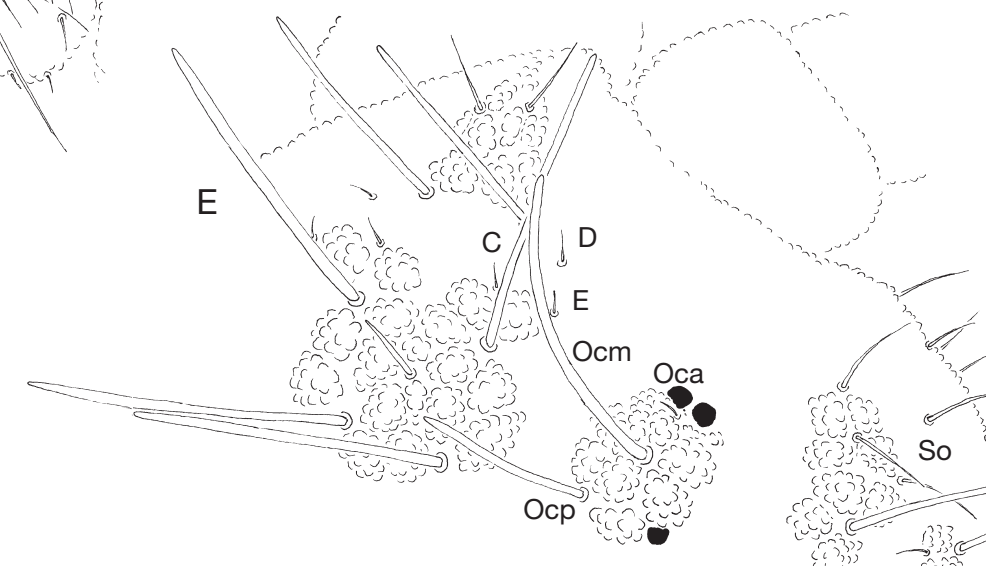

D

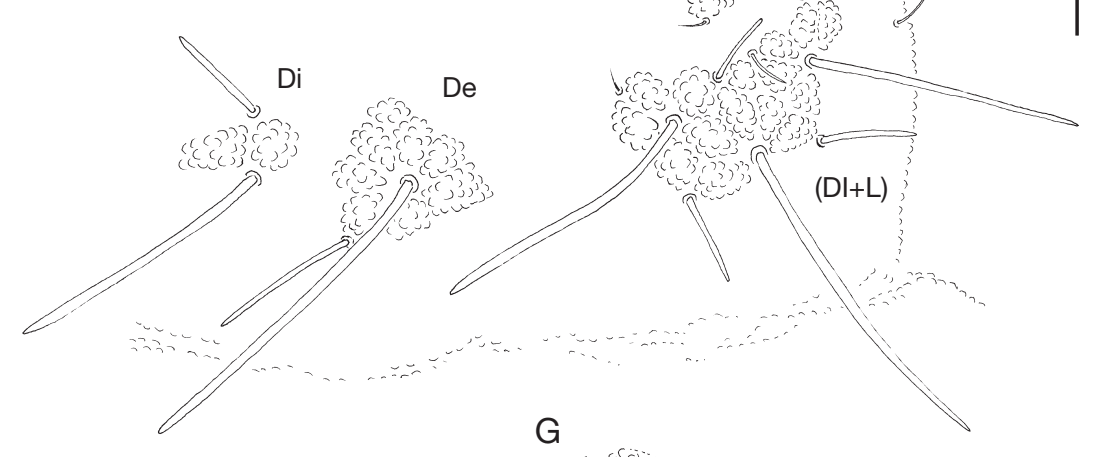

Th. III
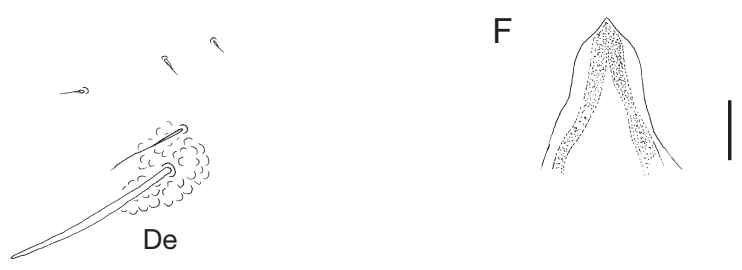

G

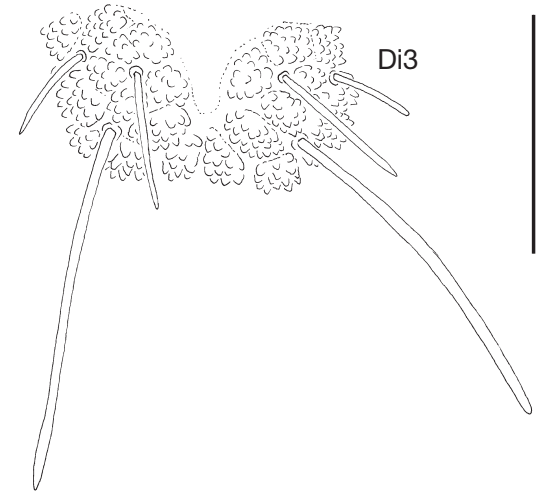

FIG. 5. - A, B, D, Neanura minuta Gisin, 1963: A, ventral chaetotaxy of Abd. IV-VI; B, chaetotaxy of head, dorsolateral view; D, chaetotaxy of group De of Th. II-III; C, N. pallida Deharveng, 1979: chaetotaxy of group De of Th. III.; E, N. pseudoparva Rusek, 1963: chaetotaxy of head, dorsolateral view; F, G, N. parva (Stach, 1951): apical part of labrum (F), tubercle (Di+Di) of Abd. V (G). Abbreviations: see Material and methods. Scale bars: A-E, G, $0.1 \mathrm{~mm}$; F, $0.01 \mathrm{~mm}$. 

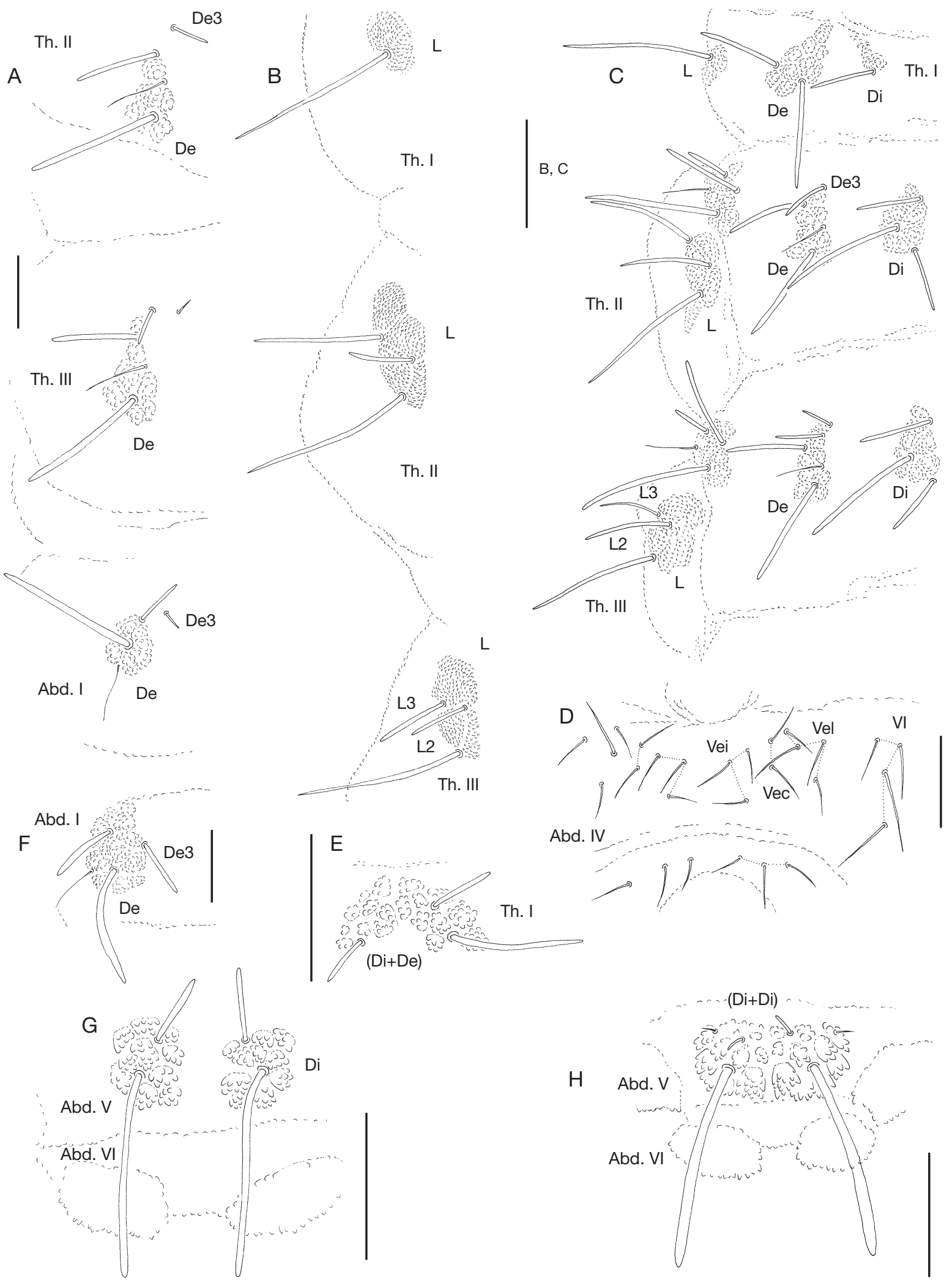

Th. I

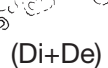

FIG. 6. - A, B, D, Neanura muscorum (Templeton, 1835): A, chaetotaxy of group De of Th. II-III and Abd. I; B, chaetotaxy of group L of Th. I-III; D, ventral chaetotaxy of Abd. IV-V; C, H, N. pseudoparva Rusek, 1963: C, chaetotaxy of Th. I-III, dorsolateral view; H, tubercle (Di+Di) of Abd. V; E, N. alba Törne, 1956: tubercle (Di+De) of Th. I.; G, N. moldavica Buşmachiu \& Deharveng, 2008: tubercles Di of Abd. V. Abbreviations: see Material and methods. Scale bars: 0.1 mm. 
1. Chaeta L' on Abd. V present (Fig. 5A), chaeta Ocp on head absent (Fig. 5B), tubercle (L+Dl) on head consist of two parts $(\mathrm{L}+1 / 2 \mathrm{Dl})$ and Dl' (Fig. $5 \mathrm{~B})$

- Chaeta L' on Abd. V absent (Fig. 2A), chaeta Ocp on head present (Fig. 5E), tubercle (L+Dl) on head not divided (Fig. 5E)

2. Body whitish to pale bluish, tubercles De of Th. II-III with $2+S$ and $3+S$ chaetae respectively (Fig. 5C) ....... ....................................................................................................... N. pallida Deharveng, 1979

- Body dark bluish, tubercles De of Th. II-III with 3+S and $4+S$ chaetae respectively (Fig. 5D) N. minuta Gisin, 1963

3. Chaetae Oca, C, E and sometimes D on head absent (Fig. 1B) .........................................................4

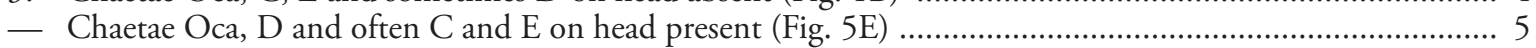

4. Labrum non ogival (Fig. 1E), chaeta Di3 on Abd. V absent (Fig. 2B) N. judithae n. sp.

- Labrum ogival (Fig. 5F), chaeta Di3 on Abd. V present (Fig. 5G) N. parva Rusek, 1963

5. Chaetae C, D and E on head present, chaetae De3 of Abd. I-III free (Fig. 6A), chaeta L2 of Th. III shorter than L3 (Fig. 6B), group Vei of Abd. IV with three chaetae (Fig. 6D) .............. N. muscorum* (Templeton, 1835)

- Chaetae De3 of Abd. I-III fused with tubercles De (Fig. 6F), chaeta L2 of Th. III longer than L3 (Fig. 6C), group Vei on Abd. IV with two chaetae

6. Tubercles Di and De of Th. I fused (Fig. 6E)

7. Chaeta Di3 of Abd. V present (Fig. $6 \mathrm{H}$ ), tubercles Di of Abd. V fused (Fig. 6H) or sometimes separate .......

- Chaeta Di3 of Abd. V absent (Fig. 6G), tubercles Di of Abd. V always separate (Fig. 6G) N. pseudoparva Rusek, 1963 N. moldavica Buşmachiu \& Deharveng, 2008

* Neanura persimilis Mills, 1934 from Iowa (USA), insufficiently described, is provisionally considered as a synonym of $N$. muscorum (Templeton, 1835).

as a consequence, proposed as the first model organism among the family Neanuridae (Hoskins et al. 2015). In addition, the figures presented herein can also help to verify data for this species, which has been recorded from almost the entire world except Antarctica. The parthenogenetic character of most of its populations probably explains such a wide distribution of the species, though bisexual populations are present in a stripe across central France, that need to be re-examined morphologically (Cassagnau 1972; Deharveng 1982).

In contrast to Neanura muscorum, most Neanura species have narrow ranges, often limited to central Europe. It is noteworthy, however, that this picture is far from complete and may be incorrect due to our poor knowledge about Neanurinae of the Balkan peninsula. Considering fauna of Collembola, this region is surely one of the underrepresented and least recognized in this respect on the continent.

Finally, Neanura judithae n. sp. is probably really endemic to the Tatra Mts since it has been never recorded outside this mountain range despite many investigations conducted in different parts of the Western and Eastern Carpathians. The Tatra Mts, located in the centre of the Western Carpathians on territory of Poland and Slovakia, cover a small size area $\left(800 \mathrm{~km}^{2}\right)$, but they represent the highest mountain massif within the whole Carpathians. Furthermore, they are the highest mountains between the Alps and the Caucasus as well as between the Scandinavian and Balkan peninsulas. They show a truly alpine character and landscape with glacial cirques, hanging valleys and postglacial lakes (Fig. 4). This mountain massif is commonly known as the centre of occurrence of highmountain biodiversity in this part of the continent as well as the northernmost centre of endemism connected with mountains of the alpine system. Among Collembola, three species to date are recognized as endemic of the Tatra Mts: Tetracanthella carpathica Stach, 1947 (Smolis \& Skarżyński 2006); Stachorutes tatricus Smolis \& Skarzyński, 2001 (Smolis \& Skarżyński 2001); Ceratophysella michalinae Skarżyński, 2005 (Skarżyński 2005). It is noteworthy that $N$. judithae n. sp. is the first known Neanurinae endemic to this remarkable mountain range.

\section{Acknowledgements}

We thank Mikhail Potapov and an anonymous reviewer for their comments on the manuscript.

\section{REFERENCES}

Bellinger P. F., Christiansen K. A. \& Janssens F. 2016. — Checklist of the Collembola of the world. Available from: http://www. collembola.org (accessed on 20.VI.2016).

BuşMachiu G. \& Deharveng L. 2008. — Neanurinae and Morulininae of Moldova (Collembola: Neanuridae), with description of Neanura moldavica sp. nov. Zootaxa 1714: 61-66. 
CASSAGNAU P. 1972. — Parthénogenése géographique et polyploïdie chez Neanura muscorum (Templeton), Collembole Neanuridae. Comptes rendus de l'Académie des Sciences, 274 (12): 1846-1848.

Cassagnau P. 1979. — Les Collemboles Neanuridae des Pays Dinaro-Balkaniques : leur interêt phylogénétique et biogéographique. Biologia Gallo-Hellenica 8: 185-203.

DeharVEng L. 1982. - Clé de determination des genres de Neanurinae (Collemboles) d'Europe et de la région méditerranéenne, avec description de deux nouveaux genres. Travaux de Laboratoire d'Écobiologie des Arthropodes édaphiques, Toulouse 3 (4): 7-13.

Deharveng L. 1983. - Morphologie évolutive des Collemboles Neanurinae en particulier de la lignée néanurinienne. Travaux de Laboratoire d'Écobiologie des Arthropodes édaphiques, Toulouse 4 (2): $1-63$.

Deharveng L. \& Weiner W. M. 1984. — Collemboles de Corée du Nord III-Morulinae et Neanurinae. Travaux de Laboratoire d'Écobiologie des Arthropodes édaphiques, Toulouse 4 (4): 1-61.

Deharveng L., Ait Mouloud S. \& Bedos A. 2015. - A new species of Deutonura (Collembola: Neanuridae: Neanurinae) from Algeria, with revised diagnosis of the genus and key to western Palaearctic species. Zootaxa 4000 (4): 464-472. https:// doi.org/10.11646/zootaxa.4000.4.5

Hoskins J. L., Janion-Scheepers Ch., Chown S. L. \& Duffy G. A. 2015. - Growth and reproduction of laboratory-reared neanurid Collembola using a novel slime mould diet. Scientific Reports 5: 11957: 1-8. https://doi.org/10.1038/srep11957

MaCGillivraY AD 1893. - North American Thysanura - IV. Canadian Entomologist 25 : 313-318.

MaYvan M. M., SHAYANMEHR M., SMOlis A. \& SKARŻYŃSKI D. 2015. - Persanura hyrcanica, a new genus and species of Neanurinae (Collembola: Neanuridae) from Iran, with a key to genera of the tribe Neanurini. Zootaxa 3918: 552-558. https:// doi.org/10.11646/zootaxa.3918.4.4

SKARŻYŃSKI D. 2005. - Ceratophysella michalinae, a new species from Poland (Collembola: Hypogastruridae). Genus 17 (1): 1-5.

Smolis A. 2007. - Kalanura-a new genus of Neanurini (Collembola, Neanuridae, Neanurinae) from Siberia, with description of four new species. Zootaxa 1511: 1-16.

Smolis A. 2008. - Redescription of four Polish Endonura Cassagnau, 1979 (Collembola, Neanuridae, Neanurinae), with a nomenclature of the ventral chaetae of antennae. Zootaxa 1858: 9-36.

Smolis A. \& Deharveng L. 2006. - Vitronura mascula, a new species of Neanurinae (Collembola: Neanuridae) from northern Vietnam, with a key to the species of the genus. Revue suisse de Zoologie 113: 263-268. https://doi.org/10.5962/bhl.part.80349

SMOLIS A. \& KuZNETSOVA N. 2016. - Remarkable diversity of the genus Endonura Cassagnau, 1979 (Collembola: Neanuridae: Neanurinae) in the Caucasus. Zootaxa 4200 (1): 47-82. https:// doi.org/10.11646/zootaxa.4200.1.2

SMOLIS A. \& SKARŻYŃSKI D. 2001. - A new species of the genus Stachorutes Dallai, 1973 from Poland (Collembola: Neanuridae) Genus 12 (4): 407-410.

SMOLIS A. \& SKARŻYŃSKI D. 2006. - Redescription of Tetracanthella montana Stach, 1947 and T. carpatica Stach, 1947, with a key to species of the T. alpina-group (Collembola, Isotomidae). Deutsche Entomologische Zeitschrift 53 (2): 235-244. https://doi. org/10.1002/mmnd.200600019

SMOLIS A., KAHRARIAN M., PIWNIK A. \& SKARŻYŃSKI D. 2016. Endonura Cassagnau in Iran, with a key of the genus (Collembola, Neanuridae, Neanurinae). Zookeys 553: 53-71. https://doi org/10.3897/zookeys.553.6009 
